\title{
心室細動発生機構のシミュレーション解析
}

\author{
岡崎 修*1, 魏 大名*2, 春見建一*3 \\ $(* 1$ 国立国際医療センター循環器科, $* 2$ 日本光電工業株式会社, \\ *3 昭和大学藤が丘病院循環器内科)
}

心室細動 $(\mathrm{VF})$ は，心室筋細胞が無秩序に脱分極・ 再分極を繰り返すため心電図上，不規則な波形を呈 し血行動態を悪化させるので全身への循環不全から 個体死に至る危険な不整脈である。発生機序には, random reentry が関係していることが知られてい るが, とくに虚血心筋では, 正常心筋との境界領域
での reentry を形成するため致死性不整脈が起こり やすくなる。これまでに我々は武者・春見モデルで 心臓の興奮伝播が，どのような条件下で，如何なる 経過をとりVFへ移行するかについて異方向伝導 の虚血モデルを用いたシミュレーションでVF 開 始時の時相解析により, 期外刺激で誘発される VF
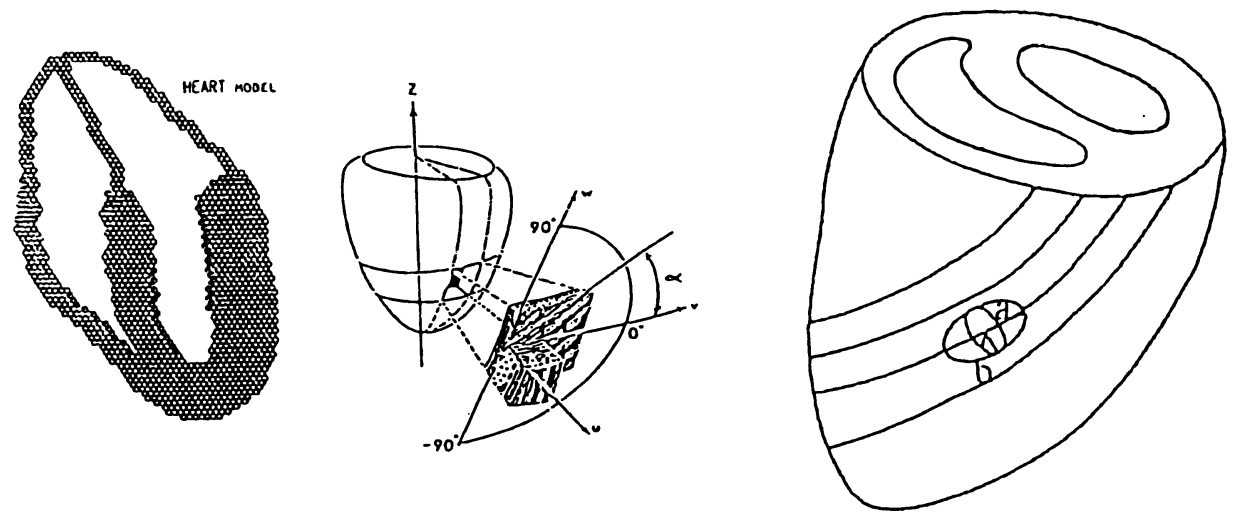

Fiber direction

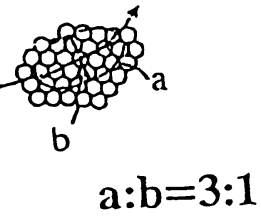

conduction velocity

\begin{tabular}{|c|c|c|c|c|c|c|c|c|}
\hline & Sinus & Atrium & AV node & His & BB & Purkinje & Vent & Ischemia \\
\hline $\mathrm{RP}(\mathrm{mV})$ & -100 & -100 & -100 & -100 & -100 & -100 & -100 & -60 \\
\hline $\mathrm{APD}(\mathrm{msec})$ & 255 & 100 & 255 & 255 & 255 & 355 & 255 & 175 \\
\hline ARP(msec) & 200 & 80 & 80 & 80 & 80 & 180 & 80 & 100 \\
\hline FRT(msec) & 295 & 120 & 295 & 295 & 295 & 295 & 395 & 242 \\
\hline CV(msec) & 0.5 & 1 & 0.1 & 2.5 & 2.5 & 2.5 & $\begin{array}{c}0.5(\mathrm{~L}) \\
0.17(\mathrm{~T})\end{array}$ & $\begin{array}{c}0.2(\mathrm{~L}) \\
0.07(\mathrm{~L})\end{array}$ \\
\hline
\end{tabular}

(RP: Resting Potential, APD: Action Potential Duration, ARP: Absolute Refractory Period, FRT: Full Recovery time, CV: Conduction Velocity, BB: Bundle Branch )

表 1 電気生理学的パラメータ 


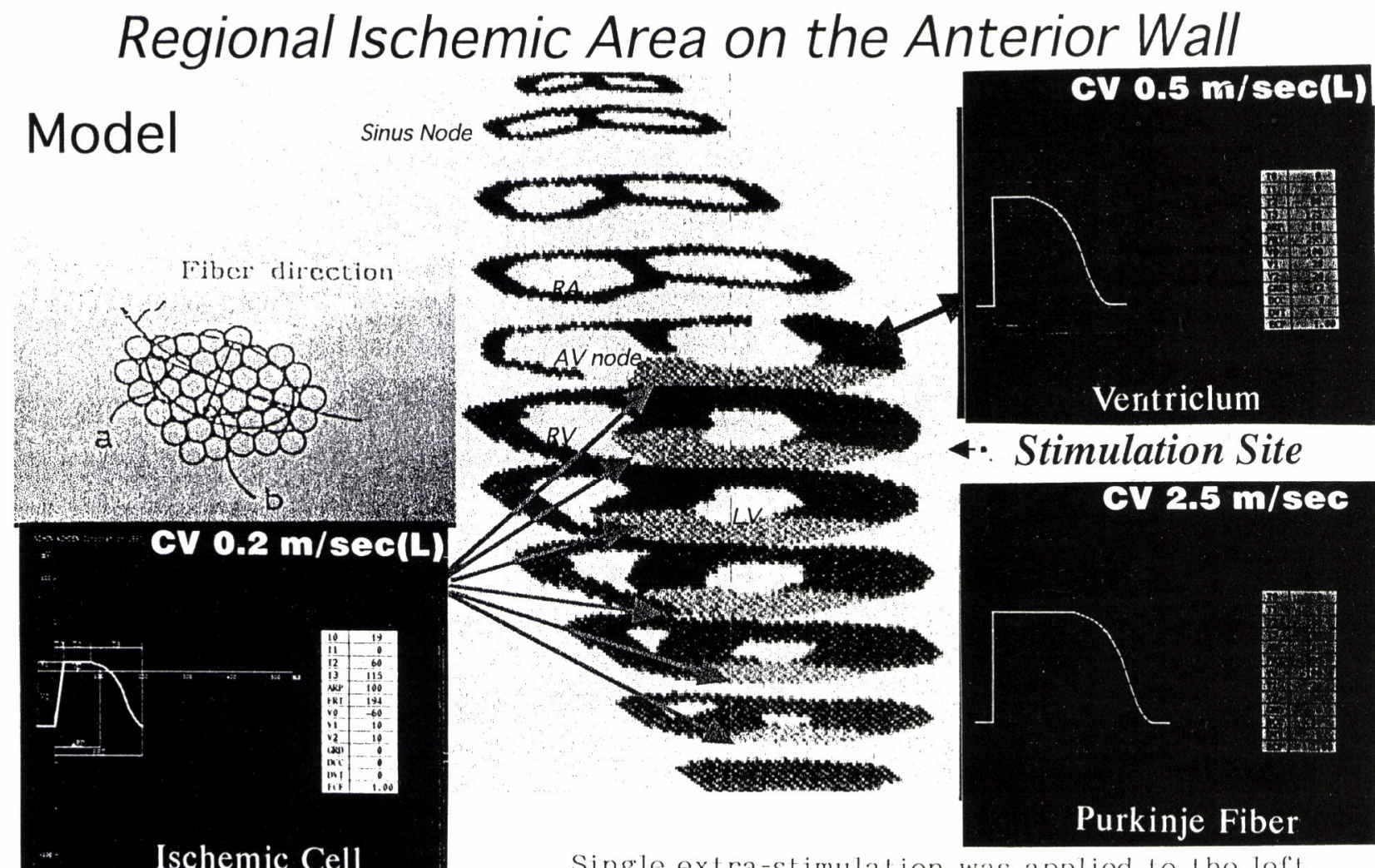

Single extra-stimulation was applied to the left ventricular surface 300 msec after the lirst sinus pacing.

図 1

について検討した結果, VF 発生には心室伝導速度 が遅延する状況下で心室筋の不応期領域が不均一に なる現象を報告してきた。連発期外刺激回数が，細 動閾値を規定する因子の一つとすると，虚血領域を 含む心筋の場合の細動発生に必要な連発数が心筋易 傷害性にどのように関係しているかを computer simulation により検討した。

心外膜から心内膜まで 5 万個からなる等分割離散 化モデルで縦横興奮伝導速度の方向比 $3 ： 1$ を有す る対称楕円体で心外膜面から心内膜面まで反時計方 向に 90 度回転させたモデルに心房・心室筋及び刺激 伝導系の電気生理学的パラメー夕；心筋活動電位持 続時間（APD）伝導速度，期外刺激連結期の変動率 (期外刺激の周期長依存性の APD 短縮する関係が あり Purkinje 線維と心室筋の期外刺激の連結期に 対する APD の短縮率を近似L, VF 発生は Purkinje 線維で 50 ～80\%, 心室筋で 9 〜 18\%の短縮率の範
囲）を代入した（表 1 ）。

ヒトTorso モデルの心位置として当てはめ体表 面電位を導出できるモデルに Miller \& Geselowitz （Circ Res 1978；43：301）の虚血条件を参考にし 心内膜下の虚血領域の伝導速度を $0.2 \mathrm{~m} / \mathrm{sec} と し$ APD 短縮した心内膜下虚血モデル及び貫壁性心筋 虚血モデルを作製した(図 1 )。心室筋の伝導速度を 縦方向で $0.5 \mathrm{~m} / \mathrm{sec}$ と遅延させ, Basic Cycle Length $500 \mathrm{msec}$ の洞刺激に P 波開始の $300 \mathrm{msec}$ 後に左室側壁表面より刺激間隔 $160 \mathrm{msec}$ の連続刺 激を与え, 誘発刺激回数の検討及び VF 発生時の isochrone mapによる時相解析を試みた。

1 ）非虚血モデルでは，心室筋細胞の APD の伝 導遅延を設定しない条件 $(\mathrm{L}=0.75 \mathrm{~m} / \mathrm{sec})$ では，心 電図は正常に導出され，最大 14 連刺激でもVF は 誘発されず，isochrone map では，不応期に相当す る領域の連続性は保たれた。 


\section{Ventricular Fibrillation}

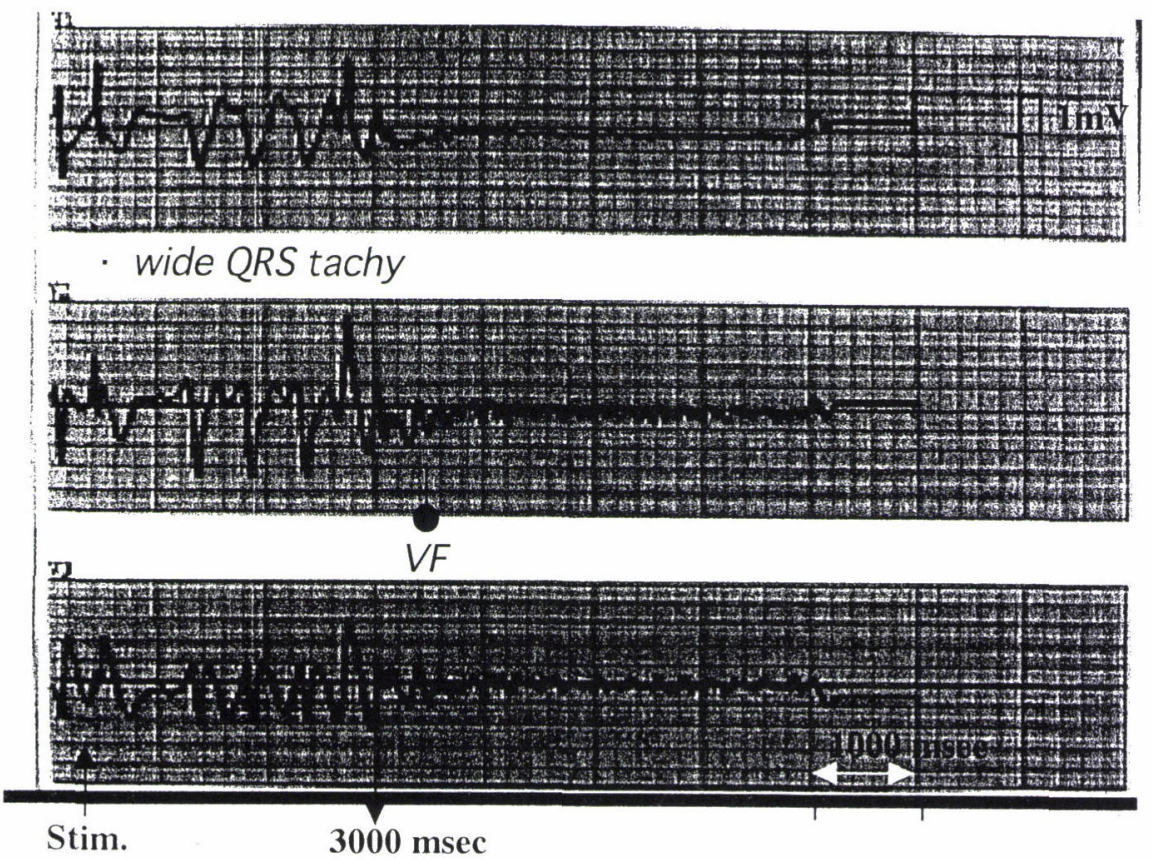

図 2

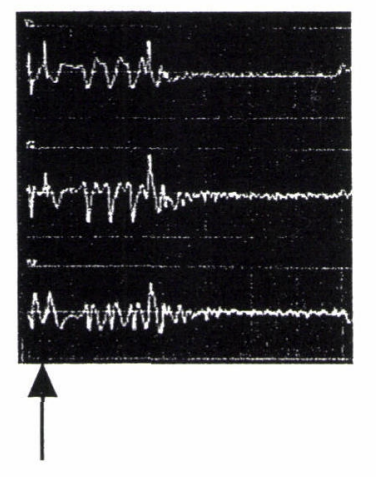

330-411 msec

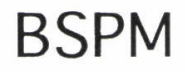

C.V. $0.2 \mathrm{~m} / \mathrm{sec}$ : ischemic zone

$0.5 \mathrm{~m} / \mathrm{sec}$ : normal 

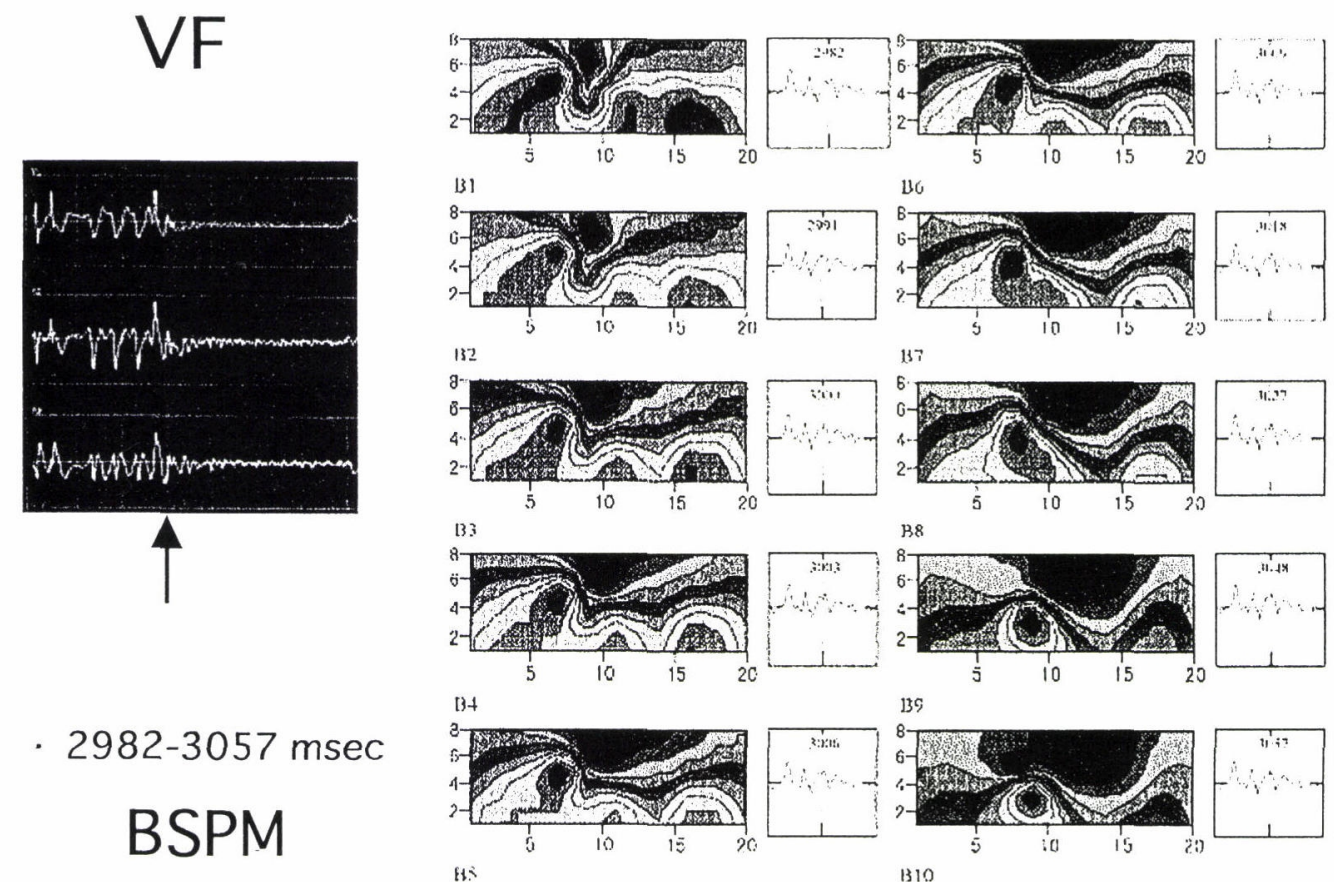

E.

1310

The corresponding BSPMs demonstrated multiple wavelets in the ischemic areas.

図 4
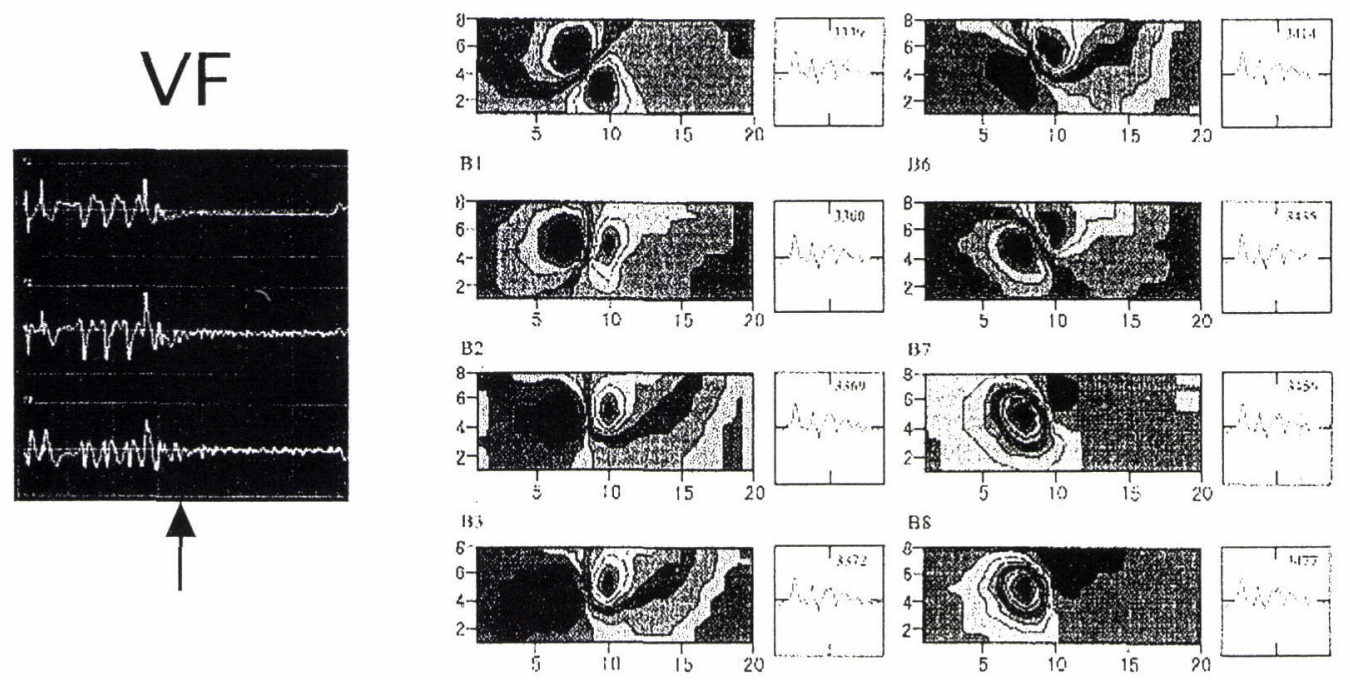

. 3339-3498 msec

BSPM
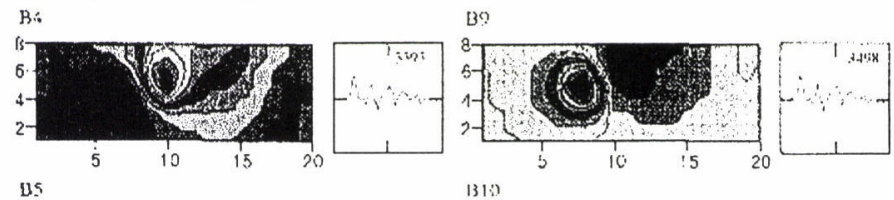

The features thus represent body surface manil'estations of the dispersion of rel'ractoriness and the forming of reentry.

図 5 


\section{Isochrone map at the initiation of Ventricular Fibrillation}
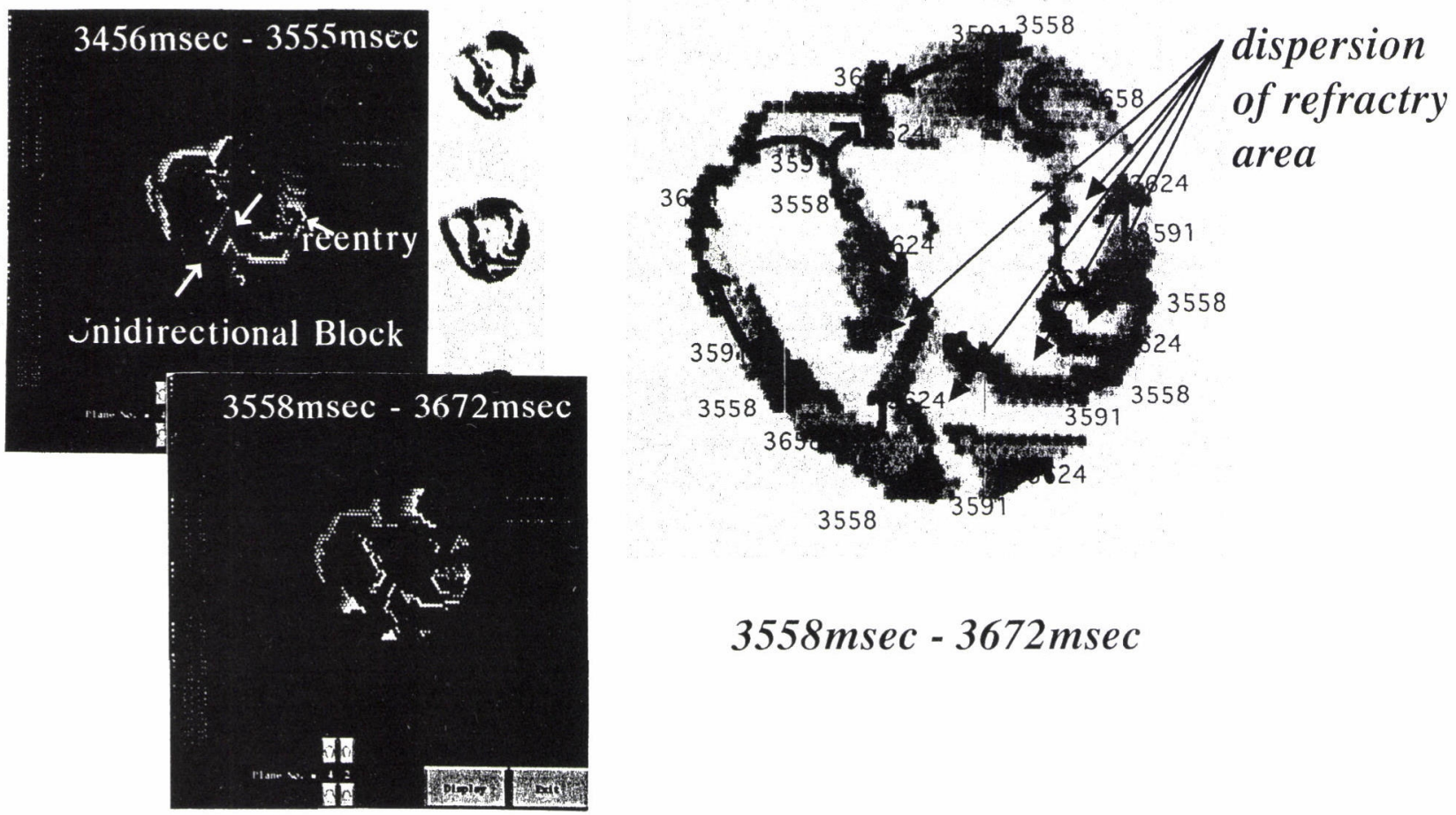

\section{$3558 m s e c-3672 m s e c$}

図 6

2 ）心内膜下虚血モデルでは 3 連刺激で VF が誘 発され, 誘発時の興奮波面は不応期が分裂しその周 辺から excitation front が不均一に開始されていた。

3 ）貫壁性前壁虚血モデルでは, 単発刺激でVF が発生（図 2 )。

時相解析では側壁から心内膜面の Purkinje 線維 を介しての刺激伝導が虚血巣の不応期の不均一性を 増加し macro reentry の形成が確認された。更に, VF 開始時の体表面心電図 (BSPM) では，極大から 極小への breakthrough が崩れ極小領域が 3 つに分 裂しVFに移行した（図3〜5).

$V F$ 開始時の時相解析から，伝導遅延を生じる虚 血領域が，伝導速度の違いから不応期の不均一性を 増加し，分裂した極小領域を形成し，細動発生に移 行していることがシミュレーションで確認された (図 6 ).

\section{伝導遅延をもたらす虚血領域の境界部の存在は，}

伝導速度の違いから不応期の不均一性が増加するた め, excitation fronts が散らばり心室細動誘発に対 する心筋易傷害性が高まると考えられた。

\section{〔文} 献]

1) Opthof T, Coronel R, Janse MJ, et al. : Electrophysiologic changes and VF in acute regional ischemia in the porcine heart: The Concept of Wavelength, J Cardiovasc Electrophysiol 3: 128, 1992

2) Josephson ME, Buxton AE, Marchlinski : Sustained VT in coronary artery disease evidence for a reentrant mechanism, in Zipes DP, Jalife J (eds) : Cardiac Electrophysiol and Arrhythmia. Orland, Grune \& Stratton, Inc, 409, 1985

3 ) Wei D, Okazaki O, Harumi K : Inducing and suppressing VF : A simulation study with three dimensional heart model and experimental data, IEEE Proc. Ann, Int Conf. IEEE EMBS, Paris $14: 400$, 
1995

4) Miller WT III, Geselowitz DB : Simulation studies of the electrocardiogram. II. Ischemia and infarction, Circ Res $43: 315,1978$

5 ) Gettes LS, Movehouse N, Surawics B : Effect of premature depolarization on the duration of action potentials in Purkinje and ventricular fibers of the moderator band of the pig heart. Circ Res $30: 66$, 1972

\section{質疑応答}

座長 杉下靖郎 (筑波大学臨床医学系内科) 杉浦 (都立広尾病院)：心室細動を起こすのに必要な 心筋量はどの位か?

岡崎：われわれのモデルでは，心室細動の発生には 伝導速度が大切であって，心筋量のみでは説明でき ない（むしろ伝導時間の方が問題である). Jancee (J Cardiovasc Electrophysid 6: 512, 1995) によれ ば, Langendorf $の$ frozen heart では, critical mass は $20 \mathrm{~g}$ という・アニソトロピー（異方向伝導）を入 れると，心室細動は起き易くなる．抗不整脈薬の効
果についても, action potential duration (APD) の短縮率が関与していると考えられる。

児玉 (名古屋大学)：このモデルから心室内刺激系を とり除いたら，リエントリー頻拍や細動は起き易く なるか?

春見 (昭和大学)：これについて発表したときは，イ ヌで心内膜側のプルキンエ線維をルゴールで灼くと, 電気刺激による心室細動の閾值を上昇させる，すな わち, 心室細動を起こし難くする,というものであっ たと思う。

飯沼（心臓血管研）：早期刺激の arrhythmogenecityは何か?

春見：モデル上，心内膜の APD が心外膜のそれよ り長いという条件下では, 正常 T 波は得られるが, 連続刺激を与えても心室細動は得られない. 先行 $\mathrm{RR}$ の短縮に伴いプルキンエ線維と作業心筋が同程 度に短縮する条件でも心室細動は起きない.プルキ ンエ線維と作業心筋の APD の短縮度が異なり, 先 行 RRの短かいところではプルキンエ線維の APD の方がより短縮して作業心筋の APD より短かくな るという条件を入れると, 5 連続刺激で心室細動が 起きた。同じ条件で，アニソトロピーの条件下では， 3 連続刺激で心室細動を生じた。 